\title{
XVIII
}

\section{O TRABALHO DO/A ASSISTENTE SOCIAL NA SAÚDE MENTAL INFANTOJUVENIL EM TEMPOS DE PANDEMIA DA COVID-19*}

\author{
Sofia Laurentino Barbosa Pereira \\ Izabel Herika Mathias Cronemberguer
}

\section{Introdução}

A pandemia da Covid-19 teve impactos devastadores em escala global, todavia, há determinados segmentos da sociedade que estão mais expostos a adoecer e a terem repercussões mais graves nas suas condições de vida e de sobrevivência, como a população que vive nas periferias, nas ruas, encarcerada, institucionalizada, assim como os indígenas, as mulheres em situação de violência doméstica e, no caso específico enfocado nesse estudo, as crianças e adolescentes em sofrimento psíquico agudo e persistente.

No Brasil, esse cenário pandêmico evidencia a agudização das expressões da questão social, na medida em que a violação dos diretos humanos básicos e a omissão do Estado diante das necessidades e ao sofrimento desses segmentos é algo histórico e que passa a ser escancarado nessa trágica conjuntura, através de um projeto perverso de necropolítica, sustentado pelo ultraliberalismo.

É nesse contexto contraditório e desafiador que o/a assistente social vai ser convocado/a a atuar, alinhado a normativa que assinala o dever de "participar de programas de socorro à população em situação de calamidade pública, no atendimento e defesa de seus interesses e necessidade", como está previsto no artigo 30 do Código de Ética Profissional (CFESS, 2012). Dessa forma, os/as profissionais de Serviço Social estão atuando em diversas frentes para mitigar os efeitos da pandemia na população, sendo desafiados/as cotidianamente a reafirmarem os compromissos, valores e princípios do seu Projeto Ético-Político, sintonizados as determinações das autoridades sanitárias competentes quanto às orientações para contenção da

*DOI- 10.29388/978-65-86678-44-4-0-f.451-472 
propagação da Covid-19, atentando para segurança dos usuários/as e dos trabalhadores, e para as suas necessidades demandadas aos serviços.

Nessa perspectiva, esse capítulo tem por objetivo discutir sobre o trabalho do/a assistente social na saúde mental infantojuvenil em tempos de pandemia da Covid-19. Trata-se de trabalho elaborado com base no referencial teórico da área, documentos normativos e orientativos do Serviço Social e no âmbito da gestão federal e local que tratam da organização institucional e do processo de trabalho no contexto do novo coronavírus, aliado a reflexões de vivências que tomam por base as experiências profissionais no Centro de Atenção Psicossocial infantojuvenil (CAPSi) Dr. Alexandre Nogueira, localizado em Teresina, Piauí.

\section{Contextualizando o Serviço Social na saúde mental}

O trabalho no campo da saúde mental é complexo, múltiplo, interdisciplinar e intersetorial e, em última instância, só prospera se estiver "colado" a uma revolução cultural do imaginário social, dos vários sujeitos e atores sociais, ou seja, constitui-se, também, como gerador de novas possibilidades anti-hegemônicas de compreender a multiplicidade e o sofrimento humano, dentro de um campo social de inclusividade e cidadanização (MERHY, 2004).

O/a assistente social é um dos profissionais demandados a atuar nesse cenário, em conjunto com uma equipe multiprofissional, constituída por médicos psiquiatras, psicólogos, enfermeiros, terapeutas ocupacionais, educadores físicos, dentre outros, tendo competência para formular análises fundamentadas e responder, de forma qualificada e na perspectiva dos direitos sociais, às diferentes necessidades apresentadas pelos/as usuários/asem sofrimento psíquico e/ou seus familiares.

É necessário reforçar que o Serviço Social é uma profissão da área da saúde, expresso na Resolução no 218, de 2007, do Conselho Nacional de Saúde. Segundo Bravo (2013), o campo da saúde é um dos setores significativos para a atuação profissional, sendo um espaço historicamente privilegiado de absorção do/a assistente social. 
Apesar de sua inserção nesse espaço sócio-ocupacional não ser recente, com a ampliação do conceito de saúde, defendido pela Reforma Sanitária brasileira, previsto na Constituição Federal e reafirmado na Lei Orgânica de Saúde, de no 8.080/90, que assegura que a saúde tem como determinantes e condicionantes a alimentação, a moradia, o saneamento básico, o meio ambiente, o trabalho, a renda, a educação, a atividade física, o transporte, o lazer e o acesso aos bens e serviços essenciais (BRASIL, 1990), houve um aumento da demanda pelo trabalho do/a assistente social. Isso se deu principalmente pela exigência de um/a profissional capacitado para atuar frente aos determinantes sociais dos processos saúde-doença, que se traduzem em necessidades de saúde, e são entendidos como produtos das relações sociais e dessas com o meio físico, social e cultural.

Nesses termos, o/a assistente social vai atuar com as demandas postas pelos/as usuários/as do Sistema Único de Saúde (SUS), que envolvem uma diversidade de determinantes sociais que se relacionam às condições reais de vida dos indivíduos. Com base nessas reflexões, entende-se que o trabalho profissional, tanto na política de saúde quanto nas demais políticas sociais em que se insere no Brasil, é determinado pelas contradições próprias do capitalismo, atuando principalmente no enfrentamento de situações de violações de direitos que afetam as condições de vida da população em geral e, sobretudo, dos setores mais empobrecidos da sociedade.

Nessa direção, é necessário retomar lamamoto (2015), para compreender que é na questão social que o Serviço Social encontra o seu objeto de trabalho, pois é ela que provoca a necessidade de intervenção desse profissional em suas múltiplas determinações, tal como vivenciadas pelos indivíduos sociais em suas relações cotidianas.

Na saúde mental não é diferente, na medida em que a profissão atua sobre as refrações da questão social que se manifestam a partir da exclusão da pessoa em sofrimento psíquico do sistema produtivo e do convívio social pelo estigma social que passou a fazer parte da sua identidade, haja vista ser considerado, historicamente, pela sociedade, como uma pessoa perigosa e incapaz, portanto, que deveria ser excluída do convívio social. Além do próprio histórico de exclusão social desse segmento, que se traduz no imaginário social da soci- 
edade na expressão comum de que "lugar de louco é no hospício", e do estigma e preconceito que passou a rondar esses sujeitos e seus familiares (PEREIRA, 2017).

Dessa forma, a partir de sua formação generalista no campo das ciências sociais aplicadas, os/as assistente sociais desenvolve um conjunto de habilidades e competências que permitem uma concepção ampliada de saúde, a partir de uma visão de totalidade dos sujeitos e das manifestações da questão social que perpassam as suas condições de vida e de reprodução social, buscando respostas na esfera da viabilização dos direitos.

E, no campo da saúde mental, são as múltiplas e complexas expressões da questão social que permeiam a vida das pessoas em sofrimento psíquico e suas famílias que se apresentam como demandas concretas de trabalho para os assistentes sociais nos diversos dispositivos da Rede de Atenção Psicossocial (RAPS). Tais demandas têm relação com as precárias condições de sobrevivência vivenciadas por esses sujeitos, relacionados ainda ao desmonte do conjunto de políticas sociais, sobretudo da Seguridade Social, e a consequente negação de muitos direitos humanos e sociais previstos na Carta Magna (PEREIRA, 2020).

Assim, na sua inserção nos serviços de atenção psicossocial, o/a assistente social vai lidar cotidianamente com situações singulares vividas pelos sujeitos em sofrimento psíquico e seu núcleo familiar, que são atravessadas por determinações de classe, gênero e etnia, buscando respostas que viabilizem o acesso aos direitos a esse segmento, que historicamente teve negada a sua condição de cidadania.

A pandemia do novo coronavírus escancara a histórica e estrutural desigualdade social existente no país, tendo como consequência a agudização das manifestações da questão social, o que vai gerar novas, complexas e heterogêneas demandas aos/as assistentes sociais nos diversos espaços em que atuam - como será discutido no próximo tópico, que apresenta reflexões sobre os impactos da pandemia no modus operandi do trabalho da/o assistente social na saúde mental infantojuvenil. 


\section{A Pandemia da Covid-19 e os impactos no trabalho da/o assistente social no campo da saúde mental infantojuvenil}

A pandemia da Covid-19, declarada como emergência de saúde pública pela Organização Mundial de Saúde (OMS) em 30 de janeiro de 2020, também definido pelo Ministério da Saúde em 03 de fevereiro de 2020, demandou a adoção de medidas de prevenção, controle e contenção de riscos, danos e agravos à saúde pública. Nessa direção, o Ministério da Saúde (MS) emitiu a Nota Técnica nำ12/2020 sobre o funcionamento dos dispositivos da RAPS na pandemia, entendidos como serviços essenciais e que, portanto, devem continuar ofertar cuidado e assistência a população, entretanto, recomendam a suspensão temporária das atividades em grupo e coletivas e a redução da circulação de pessoas, em respeito às medidas de distanciamento social e aos riscos iminentes a saúde dos usuários e profissionais (BRASIL, 2020).

Tais medidas têm um custo social e de saúde mental muito significativo, sobretudo para as pessoas com agravamento psíquico severo e persistente, que tinham atendimento regular nos Centros de Atenção Psicossocial (CAPS) e viam esse serviço não apenas como um espaço de tratamento ao transtorno mental, mas como local de socialização, construção de vínculos e lazer. Assim, a saúde mental ganha destaque maior no atual do contexto da pandemia, na medida em que são estimados impactos psicossociais diversos em decorrência do novo coronavírus (FIOCRUZ, 2020). Essa situação se agrava para os grupos em situação de vulnerabilidade, como é o caso das crianças e adolescentes que já sofriam com transtornos mentais severos e persistentes antes da pandemia, bem como suas famílias.

É necessário destacar que a infância brasileira é marcada por extrema pobreza e não acesso aos Direitos Fundamentais (UNICEF, 2018; IBGE, 2018) e, no cenário atual da Covid-19, crianças e adolescentes em vulnerabilidade social são gravemente afetados, pois são suscetíveis a déficits históricos que perpassam gerações, como falta de saneamento, condições precárias de moradia, segurança alimentar, segurança social e acesso à saúde preventiva. 
O mais preocupante é que tudo isto se dá, não obstante o suporte da Constituição Federal (BRASIL, 1988), cujo Artigo 227 estabelece a Doutrina da Proteção Integral da Criança e do Adolescente e reconhece crianças e adolescentes como: sujeitos de direitos; sujeitos em condição de desenvolvimento peculiar; e sujeitos com prioridade absoluta. Por sua vez, a Lei Federal no 8.069/90, responsável pela instituição do Estatuto da Criança e do Adolescente (BRASIL, 1990), estabelece a destinação privilegiada de recursos para crianças e adolescentes, em seu Artigo 4으, Parágrafo Único, além de privilegiar a formulação e a execução das políticas sociais públicas e a destinação de recursos públicos visando à proteção da infância e da juventude.

Segundo Oliveira, Paiva e Rizzini (2020), a população infantil e juvenil - que representa mais de três bilhões de pessoas entre zero e 24 anos, ou $41 \%$ da população mundial - é uma das mais impactadas com a pandemia, sendo afetada por:

Violações de direitos associadas ao fechamento das escolas (ausência de meios para acessar o ensino à distância e afastamento de potencial rede de proteção), insegurança alimentar (resultado do fechamento das escolas, importante fonte de alimentação para os mais vulneráveis e decorrente da recessão econômica) e aumento da violência doméstica e sexual contra esse grupo (relacionado ao confinamento e ao uso legitimado da internet dele decorrente) (OLIVEIRA; PAIVA; RIZZINI, 2020, p. 232).

Nessa esteira, as medidas de controle e disseminação da Covid-19 têm repercussões diretas nesse segmento, uma vez que estão afastados do ambiente escolar, da convivência entre pares, do lazer e da sociabilidade, tão importantes para seu desenvolvimento, o que se agrava quando se trata de crianças e adolescentes em situação de pobreza, habitação precária, violência, falta de saneamento básico e de alimentação adequada etc.

Aliado a essas expressões da questão social que permeiam a vida de milhares de crianças e adolescentes e suas famílias no Brasil, tem-se ainda o público infantojuvenil acometido com sofrimento psíquico severo e persistente assistido pelos Centros de Atenção Psicossociais Infantojuvenis (CAPSi). Essas instituições oferecem trata- 
mento clínico e psicossocial visando à (re)inserção social dos/as usuários/as na educação, trabalho, lazer e o exercício dos direitos civis, sociais e políticos, além do fortalecimento dos seus laços familiares e comunitários. Esses dispositivos são considerados os "carros chefes" da Reforma Psiquiátrica brasileira e, portanto, estão no "olho do furacão antimanicomial" (MEHRY, 2003), pois visam construir novas práticas de cuidado em saúde mental, questionando as existentes até então no modelo hegemônico hospitalocêntrico/manicomial.

No entanto, a dinâmica da pandemia exigiu uma reestruturação desses serviços, que tiveram que reduzir suas atividades presenciais, em respeito as medidas de saúde pública, o que impactou na assistência ofertada a esse público. Nesse panorama, os/as gestores e as equipes de profissionais que atuam nos serviços assistência à saúde mental enfrentaram o desafio de (re)organização, (re)adequação e (re)invenção do seu processo de trabalho e da sua forma de ofertar cuidado nesse cenário de distanciamento social, pensando alternativas para que a população não ficasse desassistida. É nesse cenário que se encontra o/a assistente social, inserido no âmbito do trabalho coletivo em saúde e presente em diversos dispositivos da Rede de Atenção Psicossocial.

O Centro de Atenção Psicossocial II Infantojuvenil Dr. Alexandre Nogueira está localizado em Teresina, capital do Piauí e oferece um serviço multidisciplinar para crianças e adolescentes de 02 a 18 anos incompletos com transtornos mentais graves, severos e persistentes, e aqueles com histórico de uso abusivo e prejudicial de substâncias psicoativas (álcool e/ou outras drogas), além de seus familiares de referência. Vinculado ao SUS, através da Fundação Municipal de Saúde (FMS)/Gerência de Saúde Mental (GSM) de Teresina-PI, mantém horário de funcionamento das $8: 00$ hs às $18: 00 \mathrm{hs}$, de segunda-feira até sexta-feira e caracteriza-se como o primeiro CAPS infantojuvenil de gestão municipal na capital piauiense.

Em termos genéricos, o CAPSi Dr. Alexandre Nogueira acolhe, possibilita ações emancipatórias, constrói redes de encontros e vínculos, enfrenta estigmas e preconceitos, sempre visando melhorar a qualidade de vida das crianças e adolescentes atendidos e de suas famílias. Para os/as usuários/as, há intervenções interdisciplinares e transdisciplinares, quais sejam: 
1.Atendimentos individuais. 2. Grupos terapêuticos. 3. Trabalho social com as famílias mediante ações socioeducativas. 4. Atendimento individualizado às famílias. 5. Oficinas de produção que fomentem habilidades, como: artesanato, desenho e pintura. 6. Práticas de expressão e de comunicação. 7. Visitas domiciliares.8. Tratamento medicamentoso e/ou orientação medicamentosa. 9. Atividades comunitárias. 10. Práticas corporais. 11. Busca ativa. 12. Matriciamento. 13. Educação permanente sobre saúde mental para a equipe profissional. 14. Triagem. 15. Planejamento dietético / alimentação saudável. 16. Ações de articulação de Rede intrasetorial e intersetoriais. 17. Atenção às situações de crise, sempre que necessário. 18. Integralização, mormente, em datas comemorativas.

Para a consecução do proposto, o CAPSi dispõe de equipe técnica. No momento, são: três psicólogos, três assistentes sociais, uma artesã, três enfermeiras, três técnicas de enfermagem, uma nutricionista, dois psiquiatras, uma fonoaudióloga, uma terapeuta ocupacional, uma gestora e os técnico-administrativos. Em 2018, a referida instituição possuía 376 prontuários registrados: 301 ativos e 75 arquivados, de modo que, em junho de 2020 , já se tinha 872 prontuários registrados: 373 arquivados e 499 ativos. E entre março e julho de 2020 (advento da pandemia) foram realizadas 82 novas triagens, das quais 45 usuários tinham perfil grave e persistente e 37 tratavam-se em sua grande com perfil para atendimento na atenção básica e ambulatorial.

Entre os transtornos cuidados no CAPSi, destacam-se: o Transtorno do Déficit de Atenção e Hiperatividade (TDAH); Transtorno Opositivo Desafiador (TOD); Transtorno do Espectro Autista (TEA); esquizofrenia; depressão; transtorno bipolar; todos entrecruzados com a potencialização de caráter grave e/ou persistente.

Em tempos de pandemia, o CAPSi buscou adaptar o atendimento às demandas urgentes de seu público, atendendo às orientações da FMS, do MS e da OMS, tais como a Nota técnica do Ministério da Saúde no 12/2020, os Decretos estaduais no 18.884/20, $18.895 / 2020$ e $18.901 / 2020$, o Decreto municipal $n$ o $19.531 / 2020$, o Instrutivo sobre atenção psicossocial em face da pandemia do novo coronavírus (SESAPI, 2020), dentre outras normativas das gestões federal, estadual e municipal. 
Em linhas gerais, a equipe delineou um rodízio profissional, considerando as expertises e agregações profissionais, com o intuito de evitar aglomerações, direcionando à realização das seguintes atividades: consultas psiquiátricas; triagens; orientação individual; atendimento individualizado às famílias; tratamento medicamentoso e/ou orientação medicamentosa; busca ativa; matriciamento; ações de articulação de rede intrasetorial e intersetorial e atenção às situações de crise.

No que se refere ao trabalho da/o assistente social, no CAPSi, não foi diferente ao de outros espaços sócio-ocupacionais que estão nesse momento e crise sanitária, sendo este/a profissional demandado a (re)pensar seu processo de trabalho e (re)significar o cuidado das crianças, adolescentes e familiares atendidos na instituição, na medida em que tem o dever de "participar de programas de socorro à população em situação de calamidade pública, no atendimento e defesa de seus interesses e necessidade" (CFESS, 2012), como está previsto no artigo 3ㅇ do Código de Ética Profissional. Desta forma, é dever ético do/a assistente social continuar prestando auxílio e atuar para mitigar os efeitos da pandemia na população.

Desta feita, o trabalho desenvolvido pelo/a assistente social no advento da pandemia no CAPSi Dr. Alexandre Nogueira se dá, sobretudo, nas seguintes frentes: realização de atendimentos individuais com os usuários; realização de atendimentos individuais com as famílias; articulação com a rede intra e intersetorial; realização de busca ativa.

A realização dos atendimentos individuais, tanto com usuários/as, quanto com as famílias, acontece tanto na modalidade presencial quanto por teleatendimento, a depender a demanda apresentada, tendo como foco o desenvolvimento de ações socioeducativas que, segundo Abreu e Cardoso (2009), tem uma dimensão pedagógica, formadoras da cultura, ou seja, formadoras de um novo modo de pensar, sentir e agir. Reiterando essa ideia, Eiras (2012) também defende que o trabalho socioeducativo desenvolvido pelo assistente social tem um conteúdo pedagógico, de aprendizagem, voltado ao processo educativo, seja ao realizar esclarecimentos, repasses de informações, seja de mobilização para participação ou formação política 
para o efetivo exercício da cidadania e para luta contra as desigualdades sociais.

Nessa esteira, cabe destacar que, conforme os Parâmetros para atuação do/a assistente social na política de saúde (CFESS, 2009), as ações socioeducativas consistem em orientações reflexivas e socialização de informações realizadas por meio de abordagens individuais, grupais ou coletivas aos/as usuários/as, família e população e devem se constituir em eixo centro da atuação do profissional de Serviço Social. Devem ter como intencionalidade a dimensão da libertação na construção de uma nova cultura e enfatizar a participação dos usuários no conhecimento crítico da sua realidade e potencializar os sujeitos para a construção de estratégias coletivas.

No âmbito da política de saúde mental, os/as assistentes sociais, ao desenvolverem ações socioeducativas, buscam a construção de uma consciência sanitária e antimanicomial, alinhada aos princípios da Reforma Sanitária, Psiquiátrica e da luta antimanicomial. No CAPSi Dr. Alexandre Nogueira, tais ações são desenvolvidas a partir de abordagens individuais e grupais, com usuários e famílias, entretanto, no atual contexto do novo coronavírus, o trabalho socioeducativo vem sendo realizado sobretudo a partir de atendimentos individuais, conforme as determinações das autoridades sanitárias competentes quanto às orientações para contenção da propagação do vírus.

Nos atendimentos individuais às crianças e/ou adolescentes atendidos pelo CAPSi, o/a assistente social precisa se valer muito da criatividade, pela própria necessidade do serviço e pelos objetivos que se pretende alcançar, para tanto é preciso lançar mão de recursos lúdicos e artísticos e adequando sua linguagem ao público, mas sem perder de vista o objetivo das ações, tendo como norte o Projeto Ético-Político da profissão.

Em tempos pandêmicos, os atendimentos têm como foco, sobretudo, construir com o/a usuário, a partir dos recursos comunitários disponíveis na rede e de suas realidades, estratégias de enfrentar os desafios postos pela Covid-19, como a mudança na rotina, o estar em casa, o distanciamento das pessoas e também do próprio CAPS e também reafirmar para cada criança e /ou adolescente que não está só no percurso, muito embora distante da instituição. 
Em relação ao atendimento às famílias, as demandas postas no contexto do novo coronavírus têm relação, especialmente, a informações sobre o acesso à rede, serviços e benefícios socioassistenciais, tendo em vista as rápidas modificações sofridas em um curto período de tempo. E, para tanto, foi necessário realizar um intenso mapeamento sobre os serviços e benefícios existentes e a sua operacionalização.

As informações apreendidas e demandadas pelas famílias se concentram nas seguintes questões: BPC; Programa Cidade Solidária; Auxílio Emergencial; tarifa social da energia elétrica; kit alimentação; orientações sobre estratégias para o enfrentamento da violência contra mulher; acesso as Unidades Básicas de Saúde (UBS); informações sobre os serviços previdenciários, a rede socioassistencial, a Defensoria Pública, ao Ministério Público do Estado do Piauí e outros. Assim, se sobressaem as demandas de cunho socioassistencial.

Além disso, as famílias de usuários atendidos/as pelo CAPSi Dr. Alexandre Nogueira também buscavam informações e estratégias sobre como minimizar os impactos causados pela pandemia na saúde mental das crianças e adolescentes. Em resposta, foram realizadas orientações sobre interação familiar, organização da rotina familiar e sobre os fatores de risco e violências contra a criança, adolescente e a mulher, que tem aumentado nesse período pandêmico.

É necessário evidenciar que no atual contexto do novo coronavírus a família ganha centralidade e novo significado, devido à exigência de isolamento doméstico e retraimento de todos às suas residências para evitar a propagação do vírus e preservar a saúde o que, aliado ao retraimento do Estado em suas responsabilidades pela proteção social, ordenado pelo receituário neoliberal em curso, pode levar ao fortalecimento de uma perspectiva "familista" que já estava em andamento nas políticas públicas brasileiras.

Esse quadro desafiador convoca o/a assistente social a atuar em uma perspectiva "protetiva", minimizando a responsabilização da família e reduzindo o "familismo", pois, entende-se que a capacidade de cuidados e proteção da família está diretamente relacionada à proteção que lhe é garantida através das políticas públicas. Assim, reforça-se a família como instância a ser cuidada e protegida, enfatizando a responsabilidade pública, incluindo prestação de benefícios, 
transferências de recursos e serviços de qualidade com cobertura universal e de responsabilidade do Estado (TEIXEIRA, 2010; CRONEMBERGER, 2017).

Em linhas gerais, os atendimentos, seja aos/as usuários/as e ou familiares no CAPSi Dr. Alexandre Nogueira, no atual contexto pandêmico têm como foco a realização de orientações e socialização de informações sobre prevenção, contaminação e cuidados relacionados a Covid-19, bem como os impactos da pandemia nas formas de vida da população, nas relações familiares, assim como o combate ao estigma e discriminação a pessoas em tratamento ou diagnosticadas com o vírus. Ao lado dessas ações, também foi necessário o combate as "fake news" com usuários/as e familiares, procurando minimizar o bombardeio de informações falsas, prestando esclarecimentos e realizando um trabalho educativo para que, assim, fosse possível a concretização do fortalecimento e proteção social de crianças e adolescentes nesse cenário de calamidade.

Outra frente de trabalho essencial do Serviço Social no CAPSi se dá na realização de ações de articulação de rede intra e intersetorial. É necessário relembrar que os Centros de Atenção Psicossocial têm um papel estratégico na articulação e tecimento das redes, cumprindo funções de assistência direta e regulação da rede de serviços de saúde, articulando os recursos existentes em outras redes: sanitárias, assistenciais, jurídicas, cooperativas de trabalho, escolas, dentre outras (BRASIL, 2004).

Segundo pesquisa de Costa (2010), a maioria das demandas intersetoriais que chegam para a equipe no âmbito da saúde são encaminhadas ao/a assistente social, pois é visto/a como o mais capacitado/a para o desenvolvimento de habilidades que permitem responder às mais diversas necessidades sociais dos usuários, articulando várias ações e redes, estreitando as relações interinstitucionais e intersetoriais em seus diferentes espaços de atuação. Nesse horizonte, a autora destaca que a atuação do/a assistente social na política de saúde/saúde mental "funciona como tecnologia social cuja principal função é construir pontes de acesso, verdadeiros elos invisíveis entre o SUS e as demais políticas sociais, campos e órgãos" (COSTA, 2010, p. 209). 
Sobre isso, os Parâmetros para Atuação de Assistentes Sociais na Política de Saúde (CFESS, 2009, p. 30) apontam que para realizar uma atuação competente e crítica na área da saúde, cabe ao/a assistente social, dentre outras ações, "estimular a intersetorialidade, tendo em vista realizar ações que fortaleçam a articulação entre as políticas de seguridade social, superando a fragmentação dos serviços e do atendimento às necessidades sociais". Dessa forma, para viabilizar o acesso dos/as usuários/as aos seus direitos, faz-se necessário conhecer e mobilizar a rede de serviços e políticas sociais.

Na saúde mental, o território, o trabalho em rede e a articulação com outros serviços, políticas e grupos locais ganham ênfase com o novo modelo assistencial que emerge após a Reforma Psiquiátrica, e o/a assistente social se coloca como profissional estratégico para atuar no fortalecimento de articulações intra e intersetoriais. No CAPSi Dr. Alexandre Nogueira não é diferente, especialmente pela necessidade de articulação não apenas dos dispositivos da Rede de Atenção Psicossocial, mas também com os serviços da educação, assistência, habitação, lazer, cultura etc, de forma a atender as crianças e adolescentes em sua integralidade e, assim, possibilitar para o acesso e garantia dos seus direitos.

Nesse momento de crise sanitária houve uma intensa e rápida reestruturação da rotina e do funcionamento dos serviços públicos e sociais, fazendo com que o mapeamento e articulação da rede se tornem um trabalho essencial ao Serviço Social para que possa responder as demandas da população. Assim, os/as assistentes sociais do CAPSi Dr. Alexandre Nogueira realizaram intenso estudo e mapeamento sobre os serviços, programas, projetos e benefícios existentes, realizando leituras sobre as leis, portarias, documentos etc., além de estarem em constante articulação com profissionais dos demais serviços da rede.

Outra frente de trabalho do/a assistente social no CAPSi, diz respeito a realização de busca ativa dos usuários. Para tanto se utiliza como recurso o uso do telefone, com objetivo compreender e atender as especificidades demandadas por cada usuário/a e familiar, situados na sua relação com um território e que, nesse momento, estão distantes fisicamente do serviço pela imposição da crise sanitária. A busca ativa a partir do olhar do/a profissional assistente social tem 
como finalidade garantir, com informações, escuta e apreensão de suas necessidades, assim como referenciar, acompanhando de forma assertiva as demandas. Nessa direção, parte-se do entendimento da busca ativa como uma postura política de trabalho sob a bandeira da integralidade do cuidado, que pressupõe atender às necessidades de saúde para além da demanda espontânea (MATTOS, 2001).

Destaca-se ainda que, no atual contexto da Covid-19, as tecnologias de informação e comunicação ${ }^{1}$ (TICS) ganharam novo significado, se tornando ferramentas estratégicas essenciais para reduzir os impactos físicos e de saúde mental provocados pelo distanciamento social, na medida em que propiciam uma conexão entre os indivíduos, quebrando as barreiras de tempo e espaço. Dessa forma, o cenário pandêmico trouxe a ressignificação do uso de tecnologias pela sociedade de uma forma geral, mas também pelos/as trabalhadores/as dos serviços de atenção psicossocial, tais como no CAPSi Dr. Alexandre Nogueira, sendo utilizadas como instrumento de produção de relações de cuidado, "uma vez que no contato remoto os elementos centrais que se mantém são: a força do vínculo, o poder das relações e o protagonismo do/a usuário/a no seu cuidado" (SILVA; BARBOSA, 2020). Com efeito, nesse momento de excepcionalidade, as TICs passam a fazer parte do processo de trabalho das equipes dos CAPS e também dos/as assistentes sociais, como alternativa para manter o contato, o vínculo e o acompanhamento dos/as usuários/as e familiares atendidos pelo serviço.

Todavia, é necessário destacar que há uma gritante exclusão digital na sociedade brasileira e, quando se tratam de pessoas acometidas com sofrimento psíquico grave e persistente esse fato se agrava, tendo em vista que grande parcela desse segmento não tem acesso e/ou não sabe manusear computadores, celulares, tablet e/ou outras ferramentas tecnológicas e/ou não têm acesso à internet de

\footnotetext{
${ }^{1}$ Por tecnologias da comunicação e informação entende-se os recursos tecnológicos que permitem o trânsito de informações, que podem ser os diferentes meios de comunicação, assim como os meios eletrônicos que incluem as tecnologias como gravação de áudio, vídeo, as redes telemáticas, robótica e outros que, além de possibilitar novas formas de comunicação, gera novas formas de produzir o conhecimento (BRASIL, 1998).
} 
qualidade - o que não é diferente no caso do público assistido pelo CAPSi Dr. Alexandre Nogueira.

Por esse motivo, defende-se que a inclusão digital deve ser uma pauta a ser incorporada na luta antimanicomial, na medida em que os espaços virtuais precisam também ser ocupados pelas pessoas com sofrimento psíquico e seus familiares e, sobretudo no atual contexto pandêmico, em que as TICs têm sido aliado importantes para complementar as atividades de cuidado presencial que estão temporariamente suspensas em diversos serviços de assistência à saúde mental. Entretanto, frisa-se que tais atividades não substituem as presenciais, apenas complementam, tendo em vista a excepcionalidade do momento vivenciado.

Nesse ínterim (re)inventivo profissional, no CAPSi procurou-se aliar os instrumentos de trabalho já existentes potencializando-os de tal maneira a garantir o cuidado, como foi o caso do uso potencializado do telefone, do aparelho celular e de aplicativos de conversas como telegram e whatsapp para contato com usuários e famílias e também para manter o contato com a equipe e com outros serviços da rede, possibilitando (re)signitivar o fazer profissional tendo como foco o cuidado por meio da aliança informativa.

Também é preciso destacar que o Serviço Social, enquanto uma especialização do trabalho coletivo e inscrito na divisão sociotécnica do trabalho (IAMAMOTO, 2015) e parte da "classe-que-vivedo-trabalho" (ANTUNES, 2002), necessita de condições materiais e dignas para o exercício profissional, especialmente no que diz respeito a equipamentos de proteção individual e coletivo, disposição em qualidade e quantidade de máscaras de proteção, álcool em gel, água, sabão, testagem e outros.

Ademais, trabalhar na linha de frente nesse contexto emergencial afetou a subjetividade dos/as trabalhadores/as, que passaram a conviver com o medo de adoecer e/ou contaminar um membro da família, aliado a rotinas exaustivas. Esse fato merece destaque no caso do Serviço Social, tendo em vista que essa é uma profissão marcadamente feminina e que, no atual cenário de retraimento dos indivíduos e suas famílias para o espaço doméstico como estratégia de evitar a propagação do vírus, há uma ampliação da sobrecarga das mulheres, evidenciando a divisão sexual do trabalho. 
Borges e Silva (2020) reforçam essa análise, afirmando o período de distanciamento social ampliado imposto pela Covid-19 acarretou o aumento das atribuições das mulheres, na medida em que elas são histórica e culturalmente vistas como as responsáveis pelos afazeres domésticos e pelos cuidados dos filhos, idosos e pessoas com deficiência. Contexto esse que têm impactos inclusive na saúde mental dessas mulheres assistentes sociais, que também estão passiveis de adoecimento físico e psíquico.

Por fim, evidenciam-se algumas dificuldades estiveram no percurso, como: a limitação na oferta de serviços da rede; a suspensão de várias atividades que certamente trazem muitos prejuízos no cuidado em saúde mental, sobretudo ao público infantojuvenil; o retraimento dos serviços balizados pela onda da precarização das políticas públicas balizadas pelo (des)governo Bolsonaro com seu projeto econômico ultraliberal com feições neofascistas, balizadas pela necropolítica.

\section{Considerações finais}

A pandemia do novo coronavírus escancara o cenário trágico das desigualdades sociais estruturais da sociedade brasileira e evidencia a necessidade de ampliação dos investimentos do poder público em serviços e ações de cuidado e promoção da saúde mental de crianças e adolescentes, demandando diferentes áreas do conhecimento a propor formas de lidar com o contexto que permeia a crise, a fim de minimizar os impactos da pandemia do novo coronavírus na saúde mental da população. Assim como reforça a importância do Estado na garantia de proteção social integral ao público infantojuvenil e suas famílias, pois aliado a questões de saúde mental, estão o acesso à educação, habitação, trabalho, renda, transporte, cultura, lazer etc - direitos humanos básicos historicamente violados para parcela significativa de crianças e adolescentes brasileiros, bem como a suas famílias.

Nesse momento de excepcionalidade, os/as assistentes sociais que atuam no Centro de Atenção Psicossocial Infantojuvenil Dr. Alexandre Nogueira são incitados a (re)inventar o seu fazer profissio- 
nal, para serem capazes de dar respostas as demandas urgentes e múltiplas que são postas pela população infantil e juvenil acometida com transtornos mentais graves, severos e persistentes e suas famílias, sem perder de vista os compromissos e conquistas históricas acumuladas pela profissão no país nas últimas décadas, tendo como horizonte a defesa da vida.

Os/as assistentes sociais estão sendo desafiados/as cotidianamente a pensar estratégias, reafirmar os seus fundamentos e bases teóricas, políticas e técnicas, aliados as novas normativas, orientações e recomendações dos órgãos de saúde pública, de forma a preservar a sua saúde e dos/as usuários/as. Para tal, lançam mão das ferramentas tecnológicas, da criatividade e acima de tudo dos compromissos com o seu Projeto Ético-Político, congregado aos princípios da Reforma Psiquiátrica e balizados também pelo Estatuto da Criança e do Adolescente.

Por fim, é necessário evidenciar que o artigo em tela não tem a pretensão de esgotar a discussão a respeito do trabalho do/a assistente social na saúde mental, apenas trazer questões para contribuir com o debate, considerando, sobretudo os novos desafios e respostas profissionais no cenário nefasto imposto pelo novo coronavírus. Apesar de tratar de uma análise em uma realidade local de um CAPS de Teresina, capital do Piauí - Estado pobre do nordeste brasileiro espera-se que as reflexões aqui realizadas possam servir de apoio para outros estudos, contribuindo com a sistematização do fazer profissional e com o avanço das produções sobre o Serviço Social na saúde mental.

\section{Referências}

ABREU, M. M.; CARDOSO, F. G. Mobilização social e práticas educativas. In: CFESS/ABEPSS. (Org.) Serviço Social: direitos sociais e competências profissionais. CFESS/ABEPSS: Brasília, 2009.

ANTUNES, R. Adeus ao trabalho: ensaio sobre as metamorfoses e a centralidade do mundo do trabalho. 8a ed. São Paulo: Cortez, 2002.

BORGES, R. S. S.; SILVA, A. S. Distanciamento social e sobrecarga de trabalho: impactos na saúde da mulher. In: MOREIRA, E. et al (Org.). 
Em tempos de pandemia: propostas para defesa da vida e de direitos sociais. Rio de Janeiro: UFRJ, Centro de Filosofia e Ciências Humanas, Escola de Serviço Social, 2020.

BRASIL. Ministério da Saúde. CGMAD/DAPES/SAPS/MS. Nota técnica no 12/2020. Recomendações à rede de atenção psicossocial sobre estratégias de organização no contexto da infecção da COVID-19 causada pelo novo coronavírus. Disponível em: <http://189.28.128.100/ dab/docs/portaldab/documentos/notatecnica122020CGMADDAPESSAPSMS02abr2020COVID-19.pdf >. Acesso em: 30 jul. 2020.

. Ministério da Saúde. Secretaria de Atendimento à Saúde. Departamento de Ações Programáticas Estratégicas. Saúde mental no SUS: os Centros de Atenção Psicossocial. Brasília: Ministério da Saúde, 2004.

. Secretaria de Educação Fundamental. Parâmetros Curriculares Nacionais: terceiro e quarto ciclos do ensino fundamental: introdução aos parâmetros curriculares nacionais. Brasília: MEC/SEF, 1998.

. Lei n. 8.069, de 13 de julho de 1990. Dispõe sobre o Estatuto da Criança e do Adolescente (ECA) e dá outras providências.

. Lei no 8.080, de 19 de setembro de 1990. Dispõe sobre as condições para a promoção, proteção e recuperação da saúde, a organização e o funcionamento dos serviços correspondentes e dá outras providências.

. Constituição da República Federativa do Brasil. Brasília: Senado Federal, 1988.

BRAVO, M. I. de S. Saúde e serviço social no capitalismo: fundamentos sócio-históricos. São Paulo: Cortez, 2013.

CFESS. Código de ética do assistente social e Lei 8.662/1993. 10. ed. rev. e atualizada. Brasília: CFESS, 2012.

. Parâmetros para atuação de assistentes sociais na política de saúde. Brasília: CFESS, 2009

COSTA, M. D. Serviço social e intersetorialidade: a contribuição dos assistentes sociais para a construção da intersetorialidade no cotidia- 
no do SUS. 2010. Tese (Doutorado em Serviço Social). Universidade Federal de Pernambuco, Recife, 2010.

EIRAS, A. A. L. A intervenção do Serviço Social no CRAS: análise das demandas e possibilidades para o trabalho socioeducativo realizado grupalmente. In: SANTOS, C. M. dos; BACKX, S.; GUERRA, Y. (Org.). A dimensão técnico-operativa no serviço social. Juiz de Fora: Editora UFJF, 2012.

CRONEMBERGER, I. H. G. M. O processo de trabalho da/o assistente social nos serviços de acolhimento institucional no Estado do Piauí. 2017. 316 f. Tese (Doutorado em Políticas Públicas). Universidade Federal do Piauí, Teresina, 2017.

FUNDAÇÃO INSTITUTO OSWALDO CRUZ - FIOCRUZ. Saúde mental e atenção psicossocial na pandemia COVID-19 - recomendações gerais. Rio de Janeiro: Fiocruz, 2020.

FUNDO DAS NAÇÕES UNIDAS PARA A INFÂNCIA - UNICEF. Pobreza na infância e adolescência. Brasília, 2018. Disponível em: <https:// www.unicef.org/brazil/ relatórios>. Acesso em: 4 mai. 2020.

IAMAMOTO, M. V. O serviço social na contemporaneidade: trabalho e formação profissional. 26a ed. São Paulo: Cortez, 2015.

INSTITUTO BRASILEIRO DE GEOGRAFIA E ESTATÍSTICA - IBGE. 20172018. Síntese de indicadores sociais. Brasília, 2017-2018. Disponível em: <https://agenciade noticias.ibge.gov.br>. Acesso em: 5 mai. 2020.

MATTOS, R. A. Os sentidos da integralidade: algumas reflexões acerca de valores que merecem ser defendidos. In: PINHEIRO, R.; MATTOS, R. A. (Org.). Os sentidos da integralidade na atenção e no cuidado à saúde. Rio de Janeiro: UERJ-IMS, ABRASCO, 2001.

MEHRY, E. E. Os CAPS e seus trabalhadores: no olho do furacão antimanicomial. Alegria e alívio como dispositivos analisadores. In: $\mathrm{MEH}-$ RY, E. E.; FRANCO, T. B. (Org.). Trabalho, produção de cuidado e subjetividade: textos reunidos. São Paulo: Hucitec, 2013.

OLIVEIRA, A. C.; PAIVA, A. R.; RIZZINI, I. As/os assistentes sociais na linha de frente: violência e violações de direitos na pandemia da CO- 
VID-19. In: LOLE, A.; STAMPA, I.; GOMES, R. L. R. (Org.). Para além da quarentena: reflexões sobre a crise e pandemia. Rio de Janeiro: Mórula Editorial/PUC-RIO, 2020.

PEREIRA, S. L. B. Saúde mental e intersetorialidade: reflexões a partir de demandas aos assistentes sociais. Ser Social. Brasília, v. 22, n. 46, p.72-98, jan./jun., 2020. Disponível em: <

https://periodicos.unb.br/index.php/SER_Social/article/view/24947> Acesso em: 16 ago. 2020.

. O processo de trabalho do serviço social na saúde mental. Teresina: EDUFPI, 2017.

PIAUÍ. Governo no Estado. Decreto no 18.895, de 19 de março de 2020. Declara estado de calamidade pública, para os fins do Art. 65 da Lei Complementar n. 101, de 4 de maio de 2000, em razão da grave crise de saúde pública decorrente da pandemia da Covid-19, e suas repercussões nas finanças públicas, e dá outras providências.

. Decreto no 18.884, de 16 de março de 2020. Regulamenta a Lei no 13.979, de 6 de fevereiro de 2020, para dispor, no âmbito do Estado do Piauí, sobre as medidas de emergência de saúde pública de importância internacional e tendo em vista a classificação da situação mundial do novo coronavírus como pandemia, institui o Comitê de Gestão de Crise, e dá outras providências. Disponível em: <https:// www.pi.gov.br/decretos-estaduais-novo-coronavirus/>. Acesso em: 31 ago. 2020.

. Decreto no 18.901, de 19 de março de 2020. Determina as medidas excepcionais voltadas para o enfrentamento da grave crise de saúde pública decorrente do Covid-19. Disponível em: <https:// www.pi.gov.br/decretos-estaduais-novo-coronavirus>. Acesso em: 31 ago. 2020.

SECRETARIA DE SAUDE DO PIAUÍ - SESAPI. Gerência de Atenção à Saúde Mental. Instrutivo sobre atenção psicossocial em face da pandemia do novo coronavírus. Disponível em: <http://www.saude.pi.gov.br/uploads/warning_document/file/510/Instrutivo_sobre_aten \%C3\%A7\%C3\%A3o_psicossocial_em_face_da_pandemia_do_novo_c oronav\%C3\%ADrus_PDF.pdf >. Acesso em: 01 ago. 2020. 
SILVA, A. P. P.; BARBOSA, A. S. O cuidado em saúde mental no cenário de pandemia da COVID-19: a experiência de (re)organização do CAPS UERJ. In: LOLE, A.; STAMPA, I.; GOMES, R. L. R. (Org.). Para além da quarentena: reflexões sobre a crise e pandemia. Rio de Janeiro: Mórula Editorial/PUC-RIO, 2020.

TEIXEIRA, S. M. Trabalho social com famílias na política de assistência social: elementos para sua reconstrução em bases críticas. Serviço Social em Revista, Londrina, v. 13, n.1, p. 4-23, jul./dez., 2010.

TERESINA. Decreto n. 19.531, de 18 de março de 2020. Declara situação de emergência em saúde pública no Município de Teresina, e dispõe sobre medidas de enfrentamento à pandemia provocada pelo novo coronavírus (Covid-19), e dá outras providências. 